TRANS · núm. $24 \cdot 2020$

MISCELÁNEA $\cdot 229-244$
El presente trabajo estudia los vínculos entre memoria y traducción —entendidos en una relación dialéctica - en la novela $L a$ casa de los conejos (Manèges. Petite histoire argentine en el original en francés) de Laura Alcoba, cuyo traductor al castellano es Leopoldo Brizuela. En el primer apartado se formula una aproximación teórica a la premisa de la lengua y lenguaje en general como formas de traducción, lo cual es punto de partida para plantear el relato del horror de la última dictadura en Argentina como forma de traducción. Se efectúa un análisis textual a partir de un término de la lengua materna que funciona como analogía de la traducción y de la memoria. La segunda parte estudia, a través de una entrevista, el trabajo de traducción que permite al traductor activar sus propios trabajos de memoria a la vez que recuperar su lengua de infancia, lo que posibilita ver la traducción como trabajo de memoria.

PALABRAS CLAVE: dictadura argentina, historia, memoria, literatura, traducción, lengua materna.

\title{
La escritura de la memoria como acto de traducción. La traducción como trabajo de memoria
}

\section{Estefanía Di MeGLIO}

Centro de Letras Hispanoamericanas (Ce.Le.His) Universidad Nacional de Mar del Plata (UNMdP) Concejo Nacional de Investigaciones Cientificas y Técnicas (CONICET)
The Writing of Memory as an Act of Translation: translation as memory work

The present paper studies the links between memory and translation - in a dialectical relationship - in La casa de los conejos (Manèges. Petite histoire argentine, in French) by Laura Alcoba. Its translator to Spanish is Leopoldo Brizuela. The first section contains a theoretical approach to the premise of language as a translation process. Besides, the paper carries out a textual analysis of a specific word of the author's mother tongue. This word is an analogy of translation and memory. The trauma account of the last Argentinean dictatorship can be formulated as a form of translation. The second section analyzes the translation work, through an interview with Brizuela. The act of translation leads the translator of memory work and allows him to recover his childhood language. This aspect makes the second part of the hypothesis possible: translation as memory work.

KEY WORDS: Argentinean dictatorship, history, memory, literature, translation, mother tongue. 
230

Y para eso nada mejor que acercar los idiomas unos
a otros (...).

Ivonne Bordelois, Del silencio como porvenir

\section{INTRODUCCIÓN}

La casa de los conejos (2008) de Laura Alcoba (Manèges. Petite histoire argentine en el original en francés, de 2007) es una novela sobre la última dictadura en Argentina (1976-1983), escrita en clave autobiográfica. Si bien la autora es argentina (nació en Cuba y pasó su primer mes de vida allí, a pesar de lo cual fue registrada en Argentina) y el español es su lengua materna, su producción literaria está escrita en francés, ya que a los diez años debió exiliarse en Francia junto a su madre, quien fuera perseguida políticamente por la Alianza Anticomunista Argentina y luego por el régimen militar. Escribir la experiencia en una lengua diferente a aquella en la que se vivieron los hechos posibilita a la autora distanciarse de ellos y contar, ficcionalmente, su historia. Esto se infiere de que en castellano debió silenciar su vivencia por múltiples causas, como la censura y la autocensura. Como contrapartida, la lengua del exilio le permitió el acto de contar, esto es, la puesta en relato de esa historia. Pero, al mismo tiempo que se distancia de la lengua materna, hay una palabra central para la historia que aun en el libro en francés se escribe en español (en parte porque no tiene traducción a otra lengua), como metáfora de un intraducible que está dado por el núcleo del trauma. La hipótesis radica en postular que los diversos niveles de traducción de la novela tienden una relación dialéctica con los trabajos de la memoria. Si partimos de la idea de que la escritura es un modo de traducción, entonces la escritura de lo traumático lo será en un segundo grado y el centro intraducible del trauma estará simbolizado por la recurrencia a la lengua materna. Por otra parte, la traducción (interlingüística e intersemiótica en el caso de la autora e interlingüística en el del traductor) activa los trabajos de la memoria.

Un primer eje del trabajo está dado por la analogía entre la escritura de lo traumático y la traducción. Desde el momento en el cual el relato de cualquier experiencia supone traducir tal experiencia al plano de lo simbólico, la narración del trauma profundiza los niveles en la dificultad de la representación. Esta última plantea un hiato entre la palabra y lo que ella denota, por lo que, junto con Steiner, puede pensarse que «hablar es traducir» (1980: 99). Desde el momento en el que el núcleo de lo traumático es aquello que queda fuera del discurso, en otras palabras, lo que difícilmente puede inscribirse ni simbolizarse, el horror que supuso la experiencia dictatorial viene a redoblar la crisis de lo representable. La vivencia traumática puede plantearse en los términos de un segundo grado de la traducción en tanto que hablar es traducir, entonces hablar de lo traumático agudiza esta acción: se trataría de traducir del lenguaje de la para-experiencia al de la experiencia cotidiana, donde juega un papel fundamental la lengua materna, en el caso de Alcoba.

El segundo eje que plantea el artículo radica en analizar parte del trabajo de traducción, llevado a cabo por Leopoldo Brizuela. Se trata de una traducción hecha a la variedad rioplatense del español. Por este motivo, la novela y su traducción permiten al traductor recuperar la lengua de la infancia. Junto con ésta, Brizuela se reencuentra con la propia historia de su vida en dictadura, la cual había estado reprimida. Prueba de ello es la propia producción literaria de Brizuela sobre el denominado pasado reciente en Argentina. 
Resta señalar que el artículo toma como material de trabajo, principalmente y además de la novela, una entrevista con el traductor, entrevista entendida también como otra forma de constitución del denominado «espacio biográfico» (Arfuch, 2018: 62-63) ${ }^{1}$.

\section{EL RELATO DEL HORROR COMO TRA- DUCCIÓN DE UNA EXPERIENCIA DIFÍCIL- MENTE TRADUCIBLE}

En el presente apartado se plantea la idea del relato de lo traumático de la dictadura como forma de traducción de esa vivencia al lenguaje simbólico, lo cual constituiría, tomando los términos de Roman Jakobson, una forma de traducción intersemiótica. Si bien en este artículo tratamos sobre la novela de Alcoba, la reflexión alude en verdad a diferentes textos de la serie narrativa sobre la última dictadura en Argentina (incluso textos no literarios, como los testimoniales) en tanto que la dificultad de la narración acerca del horror se presenta como una de las constantes que atraviesan tal serie desde sus inicios (Sarlo, 1987). Por este motivo, el análisis de esta parte se propone a la manera de un acercamiento teórico a la dificultad de hablar del horror a partir de una palabra específica de la novela en cuestión, casi como reflexión metonímica sobre la escritura del horror y su dificultad de traducción al lenguaje cotidiano. A partir de esa palabra, en una segunda instancia se ve el modo por el cual la lengua materna se formula como una de las respuestas ante esa problemática del relato de lo traumático. Por otra parte, el objetivo es tam-

I En su libro Memoria y autobiografía (2013), Leonor Arfuch plantea como una de las líneas rectoras y constantes procedimentales de las narrativas sobre el pasado reciente el elemento autobiográfico, estrechamente vinculado con la escritura de los hechos traumáticos de la dictadura (81-82). En el denominado «espacio biográfico» adquieren un rol fundamental las entrevistas en sus diferentes variantes. bién vislumbrar que la traducción interlingüística (del español —lengua de la infancia y de la vivencia relatada - al francés) activa los trabajos de la memoria y posibilita bordear lo traumatizante.

La casa de los conejos es un relato de infancia. Concretamente, la narración de una infancia en dictadura. Ya adulta, Laura, la narradora protagonista - y a la vez testigo de los hechos - cuenta la historia de su niñez durante algunos meses que abarcan el arco temporal que se extiende desde 1975 a 1976, una vez producido el golpe de Estado en Argentina. En un vaivén entre el pasado y el presente, entre una Laura niña y la ya adulta, la novela relata la historia de la llamada casa de los conejos ${ }^{2}$ en la ciudad de La Plata (capital de la provincia de Buenos Aires) en la que vivió durante algún tiempo de su infancia: se trató de una residencia que aparentemente se dedicaba a la cría de dichos animales, pero que, en verdad y de manera oculta, funcionaba como imprenta clandestina en donde se editaba la revista Evita Montonera. Diana Teruggi (personaje histórico al cual está dedicado el libro y quien se cree que es a la vez la interlocutora que plantea el texto) y su compañero y padre de su hija, Daniel Mariani, adquirieron la casa en 1975. El 24 de noviembre de 1976 la vivienda fue bombardeada por un operativo represivo de la dictadura, que arremetió durante tres horas contra la construcción y en contra de quienes se encontraban allí en ese momento. La particularidad de la denominada casa de los conejos radicaba en que en el fondo del terreno una pared móvil ocultaba las maquinarias de la imprenta. Ese espacio conformado por la pared y el lugar de la imprenta se denominaba con una palabra sin equivalentes lexicales

\footnotetext{
2 Actualmente, «la casa de los conejos», llamada «Casa Mariani-Teruggi» por los apellidos de quienes fueran sus habitantes, es un espacio para la memoria.
} 
232 en otras lenguas: «embute». Éste se constituye en uno de los términos centrales de la novela, presentado como el hilo conductor de los recuerdos que traman la memoria del personaje y de la historia que escribe. Como veremos más adelante, una de las estrategias fundamentales que encuentra la escritura de Alcoba para bordear ese trauma y poder hablar de la vivencia en dictadura es doble: por un lado, escribir en francés como forma de distanciamiento desde el idioma; en simultáneo y contrariamente, la recuperación de la lengua materna, íntimamente ligada a la memoria, que es, a su vez y como una banda de Moebius, simbolización de lo difícilmente traducible: la traducción de tal vivencia se sitúa en medio del espacio entre lenguas, a la vez que esa lengua materna presenta un término paradigmático que sólo puede traducirse con dificultad.

Si, según Steiner, hablar es traducir, entonces hablar sobre el horror en el discurso, bordear el núcleo de lo traumático en un relato que intente darle sentido sería como traducir en segundo grado, en tanto que no hay palabras para el núcleo horror y que, citando nuevamente a Steiner, lo inhumano se sitúa fuera de todo discurso (2000). Dicho en los términos de la irresoluble aporía, elaborar la narración del trauma sería como traducir lo difícilmente traducible: «"Lo traumático” da cuenta de que la cadena significante se corta, se detiene, algo que sucede queda no inscripto en el universo simbólico, queda

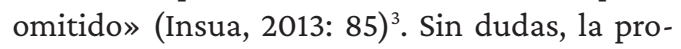
blemática de la representación se ve profundiza-

3 Así lo demuestran las reflexiones teóricas sobre el testimonio, al igual que los propios testimonios de los sobrevivientes de situaciones límites como el genocidio nazi. En este sentido, Primo Levi es un pivote de la reflexión sobre la dificultad de poner en palabras el horror vivido: «Entonces por primera vez nos damos cuenta de que nuestra lengua no tiene palabras para expresar esta ofensa, la destrucción de un hombre» (Levi, 2011: 26). da cuando al referente le es transversal el trauma, es decir, cuando lo que se quiere representar es una vivencia traumática. André Lefevere, en una postura más extrema que la de Steiner y retomando la tópica lacaniana, apunta que lo real es intraducible (1997: 76). Entonces, al decir de Alfonso Reyes, «si ya la expresión de nuestros pensamientos en nuestra habla es cosa indecisa y aproximada, el traducir, el pasar de una lengua a otra, es tarea todavía más equívoca» (1983:3).

En este punto resulta necesario postular que a la traducción interlingüística subyace la problemática de la representación lingüística, instalada por los sofistas en el siglov a. C. y retomada a inicios del siglo $\mathrm{xx}$ con un pensador pionero como Ludwig Wittgenstein, luego con las formaciones francesas de los años 60, con autores como Michel Foucault, y continuado con la denominada «revolución lingüística», con nombres como el de George Steiner. Todos estos pensadores cuestionaron el paradigma de la representación así como las reales posibilidades de representación del mundo por medio de la palabra, el lenguaje y el discurso. Sobre esta base, entonces, sabemos que no existe una relación transparente entre referente y referido, entre palabra y cosa, entre discurso y realidad(es), con lo que la idea de cualquier lenguaje como traducción ingresa en este paradigma.

Pero al mismo tiempo que el lenguaje se halla cercado por límites es condición de posibilidad. Posee un doble carácter de límite y posibilidad: mientras nombra una realidad y queda trunco en su manifestación, también la expresa en cierta medida: en su mismo seno se halla tal polaridad enunciante. Vladimir Jankélévitch, al referirse al hecho traumático por excelencia como es la muerte, lo denota en los términos de la paradoja: «En un sentido, el lenguaje es un impedimento para expresarse, pero el hombre no puede 
expresarse sino porque está impedido de expresarse. El impedimento de expresarse es el medio de expresión, porque somos hombres» (18).

Poner la experiencia en palabras, entonces, sería como traducir. Aquí subrayamos el nexo «como», a los efectos de destacar que se trata de una comparación y no del establecimiento de una equivalencia perfecta. Esto es así desde el momento en el que elegir ciertos términos y articularlos narrativamente supone la traducción de lo experiencial, en este caso, a lo simbólico, implicando su codificación lingüística. Por supuesto, entendemos la traducción en un sentido amplio, desde una concepción hermenéutica y a partir de las teorías de la abducción:

Dos vías de acceso se ofrecen al problema planteado por el acto de traducir: o bien tomar el término «traducción» en su sentido estricto de transferencia de un mensaje verbal de una lengua a otra, o bien tomarlo en sentido amplio, como sinónimo de interpretación de todo conjunto significante dentro de la misma comunidad lingüística (Ricoeur, 2005: 31) ${ }^{4}$.

Es en este sentido amplio en el que consideramos los sentidos y alcances de la traducción ${ }^{5}$.

En el caso de la novela que nos ocupa hay aun un tercer grado en la profundización de la crisis de la representación, lo que puede pensarse en tres niveles de traducción si concebimos figura-

\footnotetext{
4 Aquí es necesario formular una problemática teórica fundamental (que no nos abocamos a abordar en el presente trabajo) que involucra experiencia y lenguaje. Se trata de interrogarse si la experiencia preexiste al lenguaje o si, por el contrario, es constituida por éste. Al respecto, véase Martin Jay (2009), quien traza un recorrido abarcador de la experiencia como problema, desde la antigüedad clásica hasta autores enmarcados en el pensamiento de la posmodernidad.

5 Más aún, podría pensarse con Peeter Torop (2010) en la «traducción total» y en que se dan operaciones de traducción en cualquier hecho de la cultura (esto es, no únicamente lingüístico) donde exista desplazamiento de información.
}

damente la representación como cierto estatuto 233 de la traducción. En un primer momento (primer grado), lo real se presenta como difícilmente aprehensible por medio del discurso — así como de la percepción - El discurso hablado o escrito es, entonces, un primer instante de traducción. En una segunda instancia (segundo grado), a esta problemática viene a sumarse el hecho de que se trata de una historia atravesada por lo traumático: tenemos aquí un segundo grado en la problemática de la representación, en tanto que no hay palabras para definir o codificar el núcleo de lo traumático. Este segundo nivel de traducción valdría para los relatos que conforman la serie narrativa sobre la última dictadura en Argentina. Nora Strejilevich, refiriéndose a los sobrevivientes de la dictadura argentina, sostiene:

Los ex-detenidos que quisieran transmitir sus experiencias tendrían que reescribirlas - tendrían que crear una versión inteligible para el mundo «normal». Tendrían que traducir no sólo las palabras sino también los gestos, los matices capaces de connotar la siniestra cotidianeidad del mundo concentracionario (2006: 12). (Destacado nuestro).

En efecto, Philippe Mesnard, al analizar la figura del sobreviviente del genocidio que testimonia ante la sociedad, expresa:

El debate o la lucha entre lenguaje y experiencia que se produce en el sobreviviente se problematiza absolutamente en términos de compensación, procedimiento al que suelen recurrir los traductores para resolver problemas estilísticos intraducibles. ¿El testigo no cumple acaso la función de un traductor? (2011: 297).

En una tercera etapa (tercer grado), se halla la traducción que se efectúa de lengua a lengua, esto es, la interlingüística, diríamos con Jakobson. Así, estaríamos ante el tercer nivel de la traducción. Tal etapa se da en una doble di- 
234 rección: por un lado, Leopoldo Brizuela traduce del francés al español, pero, antes y en sentido inverso, Alcoba traduce (aunque sea de manera pre-consciente) su historia vivida en español al francés a raíz de su forzado exilio. Mario Goloboff explica la traducción que conlleva el exilio:

(...) desde el día que comenzamos a vivir en medio de una realidad que se nombraba de otro modo, emprendimos una tarea de recuperación, como si hubiéramos sido designados depositarios ante nosotros mismos de un tesoro. Las lenguas del exilio fueron imponiéndonos esa disciplina, ese destino. Frente a ellas, debimos vencer innumerables resistencias, nombrar de otra manera las cosas y a nosotros mismos, traducirnos (1990: 14).

Esta traducción de los hechos a una lengua (el francés) diferente a aquella que fue marco de tales sucesos (el español) es de capital importancia para el caso de Alcoba: escribir en francés le permite distanciarse de acontecimientos y vivencias a los que resulta difícil acercarse, en el sentido de que son de problemática elaboración (en sus diferentes alcances: elaboración tanto discursiva como, en el aspecto psicológico, de la vivencia). La traducción deviene trabajo de memoria, en el sentido en el que emplea el término Elizabeth Jelin (2012).

Sin embargo, queda un resto intraducible, en el tercer sentido o nivel de lo (no) traducible al que se refiere Paul Ricoeur ${ }^{6}$ : en la novela, se trata de esas palabras y expresiones en español en el original en francés (o en cursivas en la versión castellana, como si verdaderamente pertenecieran a otro idioma) que se presentan como metáfora de que el núcleo de lo traumático es intraducible. Siempre hay ítems léxicos que no tienen

6 Se refiere a cómo decir lo indecible en cada lengua (Ricoeur: 66). En este caso, aquello indecible está aludido por lo que no se puede decir, lo que oculta y a la vez se oculta: el «embute». traducción de una lengua a otra, o inclusive conceptos que no existen en determinada lengua. La palabra «embute», entonces, es también sinécdoque de lo intraducible —o de lo difícilmente traducible por completo-, de un significado y un significante irreductibles a otra lengua: «En todas las lenguas y en sus formas, además de lo transmisible, queda algo imposible de transmitir» (Benjamin, 1971: 140). El término es, incluso, símbolo de aquello que no quiere traducirse (y no únicamente de lo que no se puede): Alcoba podría mencionar, referirse o aludir al «embute» por rodeos, perífrasis o algún otro procedimiento retórico. No obstante, opta por recurrir a la lengua materna como forma del recuerdo. La distinción entre lo indecible, lo no dicho y lo que no quiere decirse vale también para la traducción. A la vez que hay pulsión de la lengua materna, en tanto que en la novela ésta emerge como irreprimiblemente, hay también una ostensible decisión de conservar esos términos que surgen en la materialidad del lenguaje. Se trata de una opción estética, pero también política: recuperar las hablas y voces silenciadas.

Resulta de capital importancia notar que la novela no opta por un idioma o por otro. Por el contrario, la mezcla de lenguas que opera (francés y español en Manèges y jerga militante de los setenta y lengua española en $L a$ casa de los conejos) es una forma lingüística, textual y discursiva de dar cuenta de la situación intersticial de la vivencia traumática, como lo exhibe Sylvia Molloy en su ensayo Vivir entre lenguas (2015). El núcleo de lo traumatizante no se emplaza en una lengua o en otra, sino en el espacio intermedio entre ellas y, por extensión y simbólicamente, al margen del discurso. Este desplazamiento entre lenguas se corresponde con otros desplazamientos textuales (en cuanto a lugares - París y La Plata—, tiempos —1975 y 2006-, sujeto exi- 
liado, sujeto niño y sujeto adulto, identidades textuales y biográficas, entre otros). En simultáneo, el «embute» condensa diversas figuras del discurso: metonimia de la historia a contar (una historia alternativa que se corresponde con un lenguaje también alternativo, propio de la militancia en la Argentina setentista); también metonimia de la memoria, el recuerdo y el olvido; finalmente, analogía de la traducción y con ello de lo difícilmente traducible, analogía entonces del relato de lo traumático, en tanto que este ítem léxico de la lengua materna irrumpe en el tejido textual al igual que el trauma irrumpe en la experiencia (Benyakar, 2006) ${ }^{7}$. Podemos, pues, leerlo en analogía con el núcleo de lo traumático: así como este ítem léxico, núcleo de la historia, no tiene traducción a otra lengua (ni siquiera está registrado en el diccionario de la propia, al menos con el significado que le atribuyó la jerga de la militancia setentista), así el núcleo del horror no posee traducción al lenguaje simbólico. Entonces el relato del trauma sería una traducción en segundo grado; y en el caso de Alcoba, en tercero, en donde además se presenta la cuestión de lo difícilmente traducible, que se alude mediante el code switching emblemático (Poplack, 2001) dado por esta palabra de la lengua materna (que pertenece a la vez al habla privada, íntima $\mathrm{y}$ «clandestina»). Lo sucedido no posee correlato alguno con los vocablos que puedan llegar a pronunciarse, ya que éstos no logran subsumir la dimensión del horror: «Frente al límite de la experiencia impensable, el lenguaje requiere un

7 El doble movimiento de distanciamiento y emergencia de la lengua materna en la novela y su relación con el trauma fue abordado en el artículo Estefanía Luján Di Meglio, «Configuraciones de la lengua en La casa de los conejos de Laura Alcoba», Catedral Tomada: Revista de crítica literaria latinoamericana, 5 (9) (2017), sin paginación. Por este motivo, en el presente artículo no profundizaremos en este aspecto. “más allá de él”. Las palabras no alcanzan para nombrar lo que hay que testimoniar» (Rousseaux, 2009: 30), puesto que «lo traumático nos enfrenta a la suspensión de la palabra, lo que se plantea como lo imposible de pasar por el lenguaje» (Rousseaux, 2009: 35). Este imposible «pasar por el lenguaje» de parte (el núcleo) de la vivencia límite del trauma funda otros regímenes de la palabra y el discurso, impresos en el uso de la lengua materna como forma de exhibir que los hechos traumáticos - acaso como lo creyera Paul Celan (Friedlander, 2007: 363) sólo pueden expresarse en el idioma en el cual se vivieron. $O$, tal vez, esas palabras configuran una cartografía discursiva a modo de entender que quizá se recuerda mejor en la lengua en que se vivió la experiencia, tal como lo muestran las entrevistas de sobrevivientes del genocidio nazi. En este sentido, muchos de ellos brindan testimonio respondiendo al code-switching e intercalando, por tanto, palabras, frases y expresiones en el idioma en y con el cual se vivieron los acontecimientos (Frotscher, 2013: 182-183). A colación del vínculo entre memoria y lengua materna, Frotscher se remite a la psicología para explicarlo:

Sobre el proceso de rememoración, el psicólogo social Harald Welzer, al discutir descubiertas de las neurociencias y de la psicología cognoscitiva, apunta que el proceso de rememoración es facilitado cuando él ocurre en circunstancias sociales semejantes a aquellas de lo hecho vivido. (...) Entendemos que en una situación de entrevista, el empleo de la misma lengua usada durante los acontecimientos ocurridos en el pasado y de los cuales se trata en la conversación pueden facilitar la rememoración (182-183).

Sin embargo, recordemos que en el caso de Alcoba la solución no es radical, puesto que a la vez que recurre a su segunda lengua como forma de 
236 distanciamiento (más allá de los motivos pragmáticos) también apela al español en zonas textuales claves de su novela. Por su parte, Barbara Cassin, en La nostalgia ¿Cuándo es que, por fin, uno está en su hogar? Ulises, Eneas, Arendt (2014), pone en el foco de la investigación, a partir de la literatura y la filosofía, diferentes casos de exilio geográfico y también lingüístico e, inclusive, ejemplos de interdicción de la lengua madre (como sucede con Eneas). A partir de sus análisis, plantea la relación patente que existe entre patria, exilio y lengua materna. En este marco, sostiene la hipótesis de que el idioma materno forja la subjetividad de los individuos en una relación que es de mutua pertenencia. En tanto la memoria se halla íntimamente vinculada con la identidad, puede postularse la tríada lengua materna-identidad-memoria. Esta relación se constituye como uno de los principios constitutivos del texto en cuestión, a saber, una novela en clave biográfica en donde la lengua materna juega un rol central al momento de la memoria. De allí que la traducción del mundo de la vivencia al sistema de signos lingüísticos, la escritura de la vivencia en francés (esa traducción que permite el distanciamiento y, por lo tanto, la escritura de los bordes del horror) y la recuperación de la lengua materna que esto conlleva sean una vía que activa los trabajos de la memoria.

\section{DE LA TRADUCCIÓN COMO TRABAJO DE MEMORIA}

Como ya se ha señalado, La casa de los conejos es una traducción del texto en francés, Manèges. $\mathrm{Si}$ bien Alcoba elige la lengua del exilio por sobre la lengua materna, lo cual supone ya una relación particular con su idioma materno, lo cierto es que esta última lengua emerge en zonas centrales de la historia que reconstruye el texto. Por esta razón, el sujeto de la enunciación recupera la lengua de su infancia al mismo tiempo que recobra la historia que vivió y, las dos juntas, permiten en última instancia la reconstrucción de cierta parte de la identidad. Concretamente, rehace su historia por medio del encuentro con un idioma. Algo similar a esto que ocurre con el sujeto que enuncia, le sucede al traductor, Leopoldo Brizuela (como la autora, nacido en la ciudad de La Plata, capital de la Provincia de Buenos Aires), quien al trabajar con el lenguaje como materia prima de su labor logra recobrar esa lengua de infancia. Si antes señalábamos el quiebre en el plano del discurso provocado por la experiencia traumática, ahora será la lengua, como en el caso de la protagonista de la novela de Alcoba, la que suscite el recuerdo y reconstruya una memoria que ha permanecido obturada. De igual manera, mientras antes decíamos que hay hueco y vacío de simbolización, ahora una parte componente del lenguaje (la lengua, concretamente la materna) va indisociablemente unida al recuerdo de una época particular: la infancia, vinculada ella a acontecimientos políticos y sociales bien específicos. Así como un aroma o un sabor pueden convocar el recuerdo -el ejemplo literario paradigmático lo hallamos en la magdalena de Proust - una palabra es capaz de actualizar el recuerdo y enhebrar la memoria. La experiencia que hace a la propia vida se ramifica en nuevas direcciones, desplegando nuevos sentidos. La traducción habilita el espacio para el resurgir de la experiencia personal, de la historia de vida propia, que sin dudas se liga a una historia colectiva, compartida por una comunidad.

Umberto Eco explica el hecho por todos sabido de que la traducción no implica conocer solamente un idioma, sino también dominar ciertas competencias que se relacionan con él: «[...] una traducción no depende sólo del contexto lingüís- 
tico, sino también de algo que está fuera del texto, y que denominaremos información sobre el mundo o información enciclopédica» (2013: 42). $\mathrm{El}$ solo acto de lectura puede emparentarse con la traducción. En efecto, Hans-Georg Gadamer sostiene que «leer es como traducir» (1998: 89) y que ambos son una «operación hermenéutica» (1998: 90), mientras que Steiner asegura que el lector es uno de los tantos traductores (2009: $44)$. En su caso, Brizuela no solamente domina determinadas competencias históricas, políticas y sociales que hacen a la trama y al horizonte de expectativas del texto de Alcoba, sino que, aun más, se ve atravesado por ellas: ciertos hechos y vivencias que forman parte del universo novelesco son también constitutivos de su biografía, de su identidad. En entrevista, explica Brizuela:

Lo que pasa es que siempre hay que traducir a un neutro. Aunque diga que no, la Argentina quiere traducciones neutras. En cambio ahí [en La casa de los conejos] yo tenía la libertad y la obligación de poner las palabras que yo usaba en la infancia y fue un viaje alucinante en ese sentido, porque empecé a recuperar cómo las usaba; no iba al diccionario. En un momento en que bautizan a la nena y la ponen en una especie de vasija, digo: «jeso es un fuentón!», como tenía mi abuela. Y en mi memoria empezó a aparecer toda esa época del '73, en la que yo era un poquito más grande que Laura, cinco años más (Di Meglio, 2019: 281).

Brizuela se refiere a una variable central de la tarea de traducir, que tiene que ver con la traducción a la variedad estándar de la lengua, al español «neutro». En cambio, con el texto de Alcoba este mandato del idioma neutro resulta inoperante, en tanto que la novela trabaja precisamente con una lengua de época. De esta manera, el traductor puede recuperar las palabras que él mismo empleaba su infancia. Es él quien expresa esto con la antítesis paradojal: tenía «la libertad y la obligación de poner las palabras que yo usaba en la infancia». Habla de recobrar esas palabras que él empleaba, así como el modo en el que lo hacía. Simultáneamente, resulta interesante notar la modulación del motivo del viaje para referirse a tal experiencia: de la misma manera que con su viaje a Argentina Laura se reencuentra con el pasado y reconstruye su memoria por medio del lenguaje (el personaje de la novela reconoce explícitamente que un viaje de regreso a la Argentina actuó como motor de su escritura), Brizuela rescata una época de su vida y de la historia a partir del reencuentro con su lengua infantil. Ambos viajes terminan convirtiéndose en travesías en el tiempo que permiten desandar y rearmar así un pasado personal y colectivo. Si avanzamos en la declaración del traductor, es sintomático que afirme - nuevamente mediante una metáfora de traslación en el espacio- que «no iba al diccionario». Mientras que la protagonista de la novela «va al diccionario» (en el apartado 6 de la novela) y no encuentra la palabra que tan significativa es para ella - careciendo de significado, de palabras que puedan explicarla-Brizuela omite dirigirse a él y recurre a su diccionario propio.

Así como «embute» se convierte en palabra simbólica y paradigmática para la protagonista de la novela, «fuentón» funciona como una especie de iluminación profana - usando la noción de Walter Benjamin - para el traductor. El hecho de encontrar una perífrasis de ella en otra lengua (bassine métallique o la bassine de métal, Manèges $38 ; 39)^{8} \mathrm{y}$ en otro contexto temporal y discursivo (la actualidad de los 2000 y no la de

8 La escena en la que bautizan a Laura en el «fuentón»: «Me desvisto en la cocina y me hundo en un fuentón metálico, como aquél en que mi madre lava la ropa delicada. O a veces los repasadores, cuando están muy sucios» (Alcoba, 2008: 38). «Je me déshabille dans la cuisine et plonge dans une grande bassine métallique, comme celle où ma grandmère lave le linge fragile. Ou alors les torchons sales, quand ils sont vraiment très gras» (Alcoba, 2007: 39). 
238 los setenta; en una novela y no en la cotidianeidad de los diálogos de su infancia en la ciudad de La Plata) lleva a producir un corte por extrañamiento en el traductor, teniendo como resultado la recuperación de la lengua de infancia. Iluminación profana de acuerdo con Benjamin o satori según Barthes (1986), la palabra funciona como la magdalena de Proust, conectando directamente con esa lengua de infancia y con la memoria de esa época infantil, que coincide, por supuesto, con el período dictatorial y con la violencia política que le precedió: «Y en mi memoria empezó a aparecer toda esa época del '73».

Y es allí el punto donde el supuesto lenguaje neutro se quiebra, donde la condición «entre lenguas» está redoblada, por mezclarse el francés con el español, pero con un español no «castizo», sino subversivo, no registrado en el diccionario y asociado a memorias tampoco registradas en aquel momento, memorias alternativas, díscolas, marginales. Lengua materna y memoria, mediante la traducción, se dialectizan, se yuxtaponen y se homologan en los rasgos que las caracterizan. Nuevamente, de igual manera que «embute» hace recobrar el lenguaje de la infancia a la protagonista de la novela ya adulta y así como la palabra funciona a modo de metonimia para recordar una historia, le sucede a Brizuela con la recuperación de la lengua de infancia, mediante de un léxico particular que une el tejido de una trama lingüística y a la vez histórica. La traducción oficia de trabajo de memoria. En sus ensayos de tono aforístico sobre el lenguaje y las experiencias límites, Silvina Rabinovich entiende que:

Traducir en los momentos más contaminados de la palabra es respirar aires de esperanza. Las palabras vuelan y pueden germinar en los lugares más remotos, hasta en medio del miasma. Derrida dice que en un sentido nada es intraducible; sin embar- go, en otro, todo lo es. Traducción sería otro nombre de lo imposible (...) La traducción es resistencia obstinada ante el anhelo de territorialidad y posesión. Y es menos cambiar de lengua que cambiar su lengua y, en ella, reencontrar la extranjeridad del lenguaje. Como dice Pontalis, todas las lenguas son extranjeras. Todas vuelan de un mundo al otro (Rabinovich y Sneh, 2011: 321). (Destacados en el original).

Y acaso sea así porque «la traducción puede captar lo inefable» (Cabrera, 2016: 104), esos significados excedentes ${ }^{9}$ que permanecen fuera de toda palabra y que no son plausibles de ponerse en discurso precisamente por su carácter indecible. El traductor reconoce la lengua propia en la extranjera o, mejor, por medio de esa lengua otra. Se trata de una lengua devenida extranjera: la lengua de la infancia que ha sido perdida. Se produce una identidad a partir de ese idioma que lo conduce a un mismo tiempo al desvelamiento y a la reconstrucción de su historia personal, encuadrada en la colectiva. Alcoba lleva a cabo una puesta a distancia que es percibida por Brizuela, quien en la palabra extranjera logra descifrar lo otro, la condición de extranjería del propio idioma: una lengua cotidiana, privada, de la infancia, que se liga como por un procedimiento de simbiosis con la experiencia pasada. El traductor se desplaza de la lengua a la historia y su tarea habita en ese viaje de ida y vuelta entre una lengua ligada a la historia y una historia a la que le corresponde, casi exclusivamente, esa lengua del pasado. Mientras que la autora busca transitar un camino semiótico que consiste en poner palabras al horror vivido, el traductor, a la inversa, se topa con términos que, como las piezas de un rompecabezas, hacen

9 Jean-François Lyotard (1999) habla de lo excedente, de la diferencia o el diferendo, a propósito del testimonio y la experiencia del genocidio nazi. 
emerger su experiencia personal, conduciéndolo a reconstruirla.

Cuando se le pregunta a Brizuela específicamente sobre cómo funcionó el texto de Alcoba en relación con la propia experiencia del traductor y sus vivencias -o los recuerdos de las vivencias - de esa época, su respuesta parece estar elaborada desde las emociones: «Me revolvió toda esa época. Me devolvió el lenguaje de la infancia, nada menos». (Di Meglio, 2019: 281). Brizuela explicita una vez más que el texto le restituyó la lengua de su infancia. El lenguaje lleva inscripta la historia personal y colectiva y actualiza singulares relaciones entre las palabras y los acontecimientos históricos. Ciertos vocablos funcionan como disparadores del recuerdo $y$, por lo tanto, de la restitución de una historia que había estado reprimida. En efecto, la palabra «revolver» hace pensar en una dimensión pulsional que puede estar, a su vez, unida a la corporalidad: los sentimientos se viven y manifiestan en el cuerpo. Preguntamos a Brizuela por qué decía que le «revolvió toda esa época», si era quizá porque estaba oculta en cierto sentido. A esto contestó afirmativamente: «Y sí, estaba ahí, supongo que estaba muy reprimido» (Di Meglio, 2019: 281). Sin dudas, la novela no sólo construye memoria por medio de su propio entramado discursivo y argumental, sino que también activa los canales del recuerdo y la memoria en los lectores, igual que le sucedió a Brizuela, lector, intérprete y traductor del texto. Por otro lado, en la declaración de Brizuela surge una vez más la reflexión sobre el mandato de traducir a un idioma neutro, que invalida la idiosincrasia propia de variedades lingüísticas diferentes, asociadas a comunidades lingüísticas particulares, las cuales se vinculan, a su vez, con una historia específica. De allí que el lenguaje también haya sufrido violencia desde la época de la Colonia y de ahí que la inclusión de términos como «embute» en la novela de Alcoba esté vinculada a la recuperación de voces silenciadas y marginales de aquella historia oficial que pretendieron escribir e imponer los genocidas, antes y luego de la dictadura. En efecto, el escritor y traductor señala la diferencia de lenguajes de los diferentes personajes de la novela, como una cuestión atinente a sus ethos y a la relación lenguaje-mundo, dentro de la cual se sitúa el vínculo entre lengua e historia:

El lenguaje de los personajes en La casa de los conejos también fue muy interesante. Porque yo tenía que traducir a la narradora como a una extranjera que estaba en Francia. A los personajes no, los tenía que traducir como personas platenses [de La Plata], que hablaban jergas, porque eran militantes, eran jóvenes. Esos son los diferentes lenguajes que muestran realidades también diferentes (Di Meglio, 2019: 282).

La reflexión de Brizuela deja al descubierto que el sujeto deviene otro en su condición de exilio. Dentro de esa situación, el lenguaje del destierro se configura como una de las marcas de la otredad: el sujeto se vuelve extranjero (Berman, retomado por Ricoeur, 2005: 18), en tanto habita (y es habitado por) otro espacio y otra lengua.

Si para Alcoba el aprendizaje de otra lengua deviene directamente de una situación política como la de la dictadura, puesto que se ve obligada a aprender el francés por su también forzado exilio, la situación de Brizuela con respecto a lenguas extranjeras no será muy diferente. Cuando se le pregunta por sus inicios como traductor, contesta:

Casualmente, tiene que ver con la dictadura. En esa época, por lo menos yo, sabía que la vida estaba en otra parte. Esto era un moridero. Si que- 
rías hablar o pensar sobre determinados temas tenías que comprar un libro en inglés. Había que irse de la Argentina. Y ahí me parece que está la marca de haber aprendido otros idiomas. Aunque también es cosa de época. Había que irse afuera. Incluso para aprender sobre nosotros (Di Meglio, 2019: 280).

Y ahora ya se me pasó, pero durante muchísimo tiempo, hasta hace diez, veinte años tenía la idea de que tenía que difundir cosas, compartir lo que yo leía. Y creo que de ahí viene también la idea, no sólo de hablar otros idiomas, sino de traducir y de difundir. Primero empecé con una traductora, después durante mucho tiempo dejé y después empecé por pedido de las editoriales (Di Meglio, 2019: 280).

En otro aspecto, la memoria histórica y la reconstrucción de la historia son intrínsecas a los textos escritos sobre este período, en tanto rasgo constitutivo del acto escriturario mismo, situado en un campo literario que se vincula con el cultural, el intelectual y el político (Bourdieu, 1990). Como asevera Guillermo Saccomanno, aun cuando el escritor no lo buscare deliberadamente, se escribe como una de las modulaciones del recuerdo y la memoria (Di Meglio, 2014): individual, histórica, colectiva. Al referirse a su experiencia como traductor de la novela de Alcoba, Brizuela comenta: «Entonces fue ella la que me pidió que le tradujera La casa de los conejos. Yo lo leí, me encantó y le dije que sí. También hay una cosa un poco militante: me parecía bien, que iba a aportar ese libro» (Di Meglio, 2019: 281). La construcción de una esfera pública de la memoria, la revisión de la historia, el poner sobre el tapete las tramas individuales subsumidas por la macrohistoria o simplemente el hablar del tema son algunos de los «aportes» a los que alude el traductor. Es en esta dirección que encontramos otra de las derivas de los trabajos de la memo- ria, esto es, la contribución a conformar esa esfera de la memoria que rescata y relee el pasado, los acontecimientos, los sentidos y las versiones que durante la dictadura y los sucesivos gobiernos democráticos fueron sistemáticamente silenciados y obturados.

Por otra parte, el escritor menciona Una misma noche (2012) como texto propio que se relaciona con la escritura de lo que hasta ese entonces había permanecido bajo el velo de lo reprimido, donde lo reprimido puede leerse en una doble significación: en sus sentidos psicológicos y en su esencia de mecanismo político ${ }^{10}$. Su trabajo de traducción se tornó un desandar el lenguaje para recuperarlo, al mismo tiempo que fue el equivalente del desvelamiento de lo reprimido. En su función de traductor desentraña, aun sin buscarlo, las historias que subyacen a las palabras: la tarea de traducir se corresponde directamente con un trabajo de memoria. La traducción se halla, en este caso, directamente vinculada con la escritura del trauma: la inscripción de una historia que no había sido escrita/inscripta por efecto de la represión (política e individual al mismo tiempo). En su novela, el autor trabaja con elementos de la biografía personal, modulando la matriz discursiva de lo autoficcional, donde el protagonista, el escritor Leonardo $\mathrm{Ba}$ zán, se configura como heterónimo del nombre de autor. Incluso en ella recupera también ese lenguaje de época o, más específicamente, giros y expresiones que tenían que ver concretamente con el accionar represivo. Brizuela cuenta así que en la propia escritura de la novela continuó recordando modos del habla de esa lengua de infancia, con las palabras específicas y recurrentes de la época: «Y después trabajé (...) con

\footnotetext{
Iо «Y sí, estaba ahí, supongo que estaba muy reprimido. Y Una misma noche tiene que ver mucho con eso» (Di Meglio, 2019: 281).
} 
las palabras que nombraban en esa época: y ahí me acordé que se decía "se los llevaron”, u otro que dice que entraron en una casa y rompieron “todo, todo, todo”»(Di Meglio, 2019: 279). La dictadura marcó a tal punto cuerpos y mentes (cuando no los desapareció) que pasó a formar parte de las identidades de los sujetos, en tanto se convirtió en hito en las trayectorias individuales. De allí que la escritura se vea atravesada por ella aun cuando éste no sea el programa consciente de quien escribe: «No hay una deliberación consciente. Yo no tengo el programa de escribir sobre eso [el pasado reciente], sino que hay determinada pulsión» (Di Meglio, 2019: 277). Es que la praxis escrituraria supone poner en juego la subjetividad, hecha de experiencias, de recuerdos, de olvidos e incluso de represiones inconscientes. Al respecto, sostiene Liliana $\mathrm{He}$ ker, escritora y crítica literaria argentina:

Quiero hablar de las intromisiones de la memoria en la escritura de una ficción. No es casual que intervenga en esa escritura: nuestra memoria nos constituye, como nos constituye nuestro idioma, nuestro sexo, nuestro origen, nuestra locura personal, o el formato de nuestra nariz (1999: 104).

Así sucede en el caso de Brizuela, en el que a una práctica de escritura atravesada por la época del gobierno militar y por el estatuto de lo traumático que ello implica, no se le atribuye una deliberación o decisión consciente, puesto que es la historia personal, y por lo tanto la identidad, la que se inscribe en el proceso de escritura. Cercana a esto se halla la reflexión de Brizuela sobre la selección de la historia a contar. Cuando dice haber tomado material biográfico para la escritura del texto, manifiesta haber seleccionado escenas de su vida a las cuales no lograba atribuirles una explicación. Como si escaparan a todo entendimiento, para Brizuela no tenían un significado claro dentro de su biografía personal. El episodio de Una misma noche en el que Leonardo Bazán niño comienza a tocar el piano ante la irrupción de los militares en su casa es ficcionalización de uno de los recuerdos del autor empírico. Tal escena carece de explicación para Brizuela e inclusive se presenta como discontinua dentro del universo ficcional. En este sentido, la presencia del horror y de lo traumático (la irrupción de los militares aquella noche) provoca una suspensión de la semiosis por la cual lo traumático mismo rehúye a toda explicación acabada. De allí también que los recuerdos y las historias sean fragmentarios. La escritura se presentaría como la búsqueda y el intento de restitución de un significado ausente, como le sucede a Alcoba.

Por otra parte, resulta interesante subrayar el desafío al que se refiere Brizuela, relacionado con la palabra: cómo percibir y procesar aquello que no tiene nombre por ser una realidad, además de horrorosa y por ello mismo, nueva. Lo cierto es que aun cuando se le ponga nombre a ese dominio de lo real, cuando se apliquen conceptos a los hechos y cuando se intente mencionar lo vivido, el núcleo de ese real inaprehensible quedará fuera del discurso. Las palabras, los vocablos, los conceptos y el discurso no llegan a agotar los sentidos (y los sinsentidos) de la vivencia. En esta dirección, la mención del horror y el relato de lo traumático remiten y articulan con la primera parte del presente trabajo, en tanto que pueden plantearse análogos a la traducción: poner nombre a lo sucedido sería traducir la experiencia al sistema de signos lingüísticos, pasar de un lenguaje a otro, sabiendo que existen términos que carecen de equivalencias. 


\section{4. CONSIDERACIONES FINALES}

Algunos aspectos de la traducción son productivos para pensarlos como analogía de la época de terror vivida en la Argentina dictatorial y en sus antesalas políticas. La escritura de la historia del horror se nos presenta, aproximadamente, análoga al acto de traducir: así como hay huecos entre lengua y lengua, palabras que no se corresponden con otras, fonemas que no tienen par, cosmovisiones diversas en y por cada lengua, así la historia del trauma, inscripta fuera de los cánones de la lógica y del lenguaje cotidiano, no se corresponde con la lengua corriente. Relatar el horror es inscribir dentro del discurso una experiencia que se halla fuera de él. Sin embargo, traducción y relato del trauma no significan pérdida; por el contrario, muestran productividades (como lo señalan diversos autores en el caso de la traducción: Gadamer, 1998: 89; Panesi, 2004: 79). La traducción pre-consciente que hace Alcoba de su historia vivida en castellano se convierte en un pasar por el idioma extranjero, como quien tamiza una historia con el paso del tiempo. Se trata, aun sin buscarlo, de una operación de desautomatizar lingüísticamente para redescubrir la historia propia. Hacer extraño lo propio, convertirlo en extranjero, para luego volver a apropiarse con una nueva mirada que restituye la vivencia pasada. Esto hace que la traducción, entre otras cosas, se convierta en un mecanismo que permite activar los trabajos de la memoria. En el caso de Leopoldo Brizuela, el traductor, la dificultad de la representación de lo traumático comienza a deshilvanarse, paradójicamente, con el acto que instituyen la palabra y el lenguaje. Ese mismo lenguaje ajeno a la lógica del horror, a ese fuera de lugar y del discurso que es el trauma, es el que permite recuperar la lengua de la infancia, recordar, tomar parte en los trabajos de la memoria y reconstruir la historia para «traducirla» a las palabras del lenguaje corriente. Así, la traducción interlingüística e intersemiótica en el caso de Alcoba y la traducción interlingüística en el caso de Brizuela son las que permiten los trabajos de la memoria, activados (en ambas figuras, escritora y traductor) en conjunto con la recuperación de la lengua materna.

\section{REFERENCIAS BIBLIOGRÁFICAS}

Alcoba, Laura (2007): Manèges. Petite histoire argentine, Paris: Gallimard.

Alcoba, Laura (2010): La casa de los conejos, trad. Leopoldo Brizuela, Buenos Aires: Edhasa.

ARFuCH, Leonor (2013): Memoria y autobiografía. Exploraciones en los límites, Buenos Aires: Fondo de Cultura Económica.

ARfuch, Leonor (2018): La vida narrada. Memoria, subjetividad y política, Villa María: Eduvim.

BARTHES, Roland (1986) [1982]: Lo obvio y lo obtuso, trad. C. Fernández Medrano, Barcelona: Paidós.

Benjamin, Walter (1971) [1923]: «La tarea del traductor», trad. Hans Christian Hagedorn, en Angelus Novus, Barcelona: Edhasa, 128-143.

BENYAKAR, Moty (2006): Lo disruptivo. Amenazas individuales y colectivas: el psiquismo ante guerras, terrorismos y catástrofes sociales, Buenos Aires: Biblos.

Bourdieu, Pierre (1990) [1984]: Sociología y cultura, trad. Martha Pou, México: Grijalbo.

Brizuela, Leopoldo (2012): Una misma noche, Buenos Aires: Alfaguara.

CABRERA, Delfina (2016): Las lenguas vivas. Zonas de exilio y traducción en Manuel Puig, Ciudad Autónoma de Buenos Aires: Prometeo.

Cassin, Barbara (2014) [2013]: La nostalgia. ¿Cuándo es que, por fin, uno está en su hogar? Ulises, Eneas, Arendt, trad. Pablo Betesh, Ciudad Autónoma de Buenos Aires: Nueva visión.

Di Meglio, Estefanía (2014): «Uno escribe para olvidar. Entrevista a Guillermo Saccomanno», Contenciosa, 2 (3), <http://contenciosa.org/Sitio/VerArticulo.aspx?i=38> [consulta 20-III-2019]. 
Di Meglio, Estefanía (2019): «"Uno no escribe sobre lo que entiende”. Entrevista a Leopoldo Brizuela», Estudios de Teoría Literaria. Año 8, número 16. Pp. 276-282, <https://fh.mdp.edu.ar/revistas/index. php/etl/article/view/3445/3514> [consulta 2-V2020].

Eco, Umberto (2013) [2003]: Decir casi lo mismo, trad. Helena Lozano Miralles, Buenos Aires: Sudamericana.

FouCAult, Michel (1985) [1966]: Las palabras y las cosas, trad. Elsa Cecilia Frost, Barcelona: Planeta-Agostini.

FRIEDLANDER, Saúl (2004) [1971]: ¿Por qué el Holocausto? Historia de una psicosis colectiva, trad. Fina Warschaver, Barcelona: Gedisa.

FriedLANDER, Saul (comp.) (2007): En torno a los límites de la representación. El nazismo y la solución final, trad. Marcelo Burello, Bernal: Universidad Nacional de Quilmes.

Frotscher, Méri (2013): «Lengua, memoria e identidad. Consideraciones metodológicas sobre historias de vida de migrantes bilingües», en Robson Laverdi y Mariana Mastrángelo (comps.), Desde las profundidades de la historia oral, Buenos Aires: Imago Mundi, 173-198.

GADAMER, Hans Goerg (1998): Arte y verdad de la palabra, trad. José Francisco Zúñiga García y Faustino Oncina, Barcelona: Paidós.

Goloboff, Gerardo Mario (1990): «Las lenguas del exilio», América: Cahiers du CRICCAL, 7, L>exil et le roman hispanoaméricain actuel, 11-16, <http:// www.persee.fr/doc/ameri_0982-9237_1990_ num_7_1_1010> [consulta 12-II-2019].

HeKer, Liliana (1999): «Memoria y literatura», en Las hermanas de Shakespeare. Buenos Aires: Alfaguara, 104-112.

Insua, Gabriela (comp.) (2013): Clínica con lo traumático, Buenos Aires: Letra viva.

JAKOBSON, Roman (1975) [1959]: «On Linguistics aspects of Translation», en Reuben Brower (ed.), On Translation, Cambridge, Massachussets, Harvard University Press, 232-39.

JANKÉLÉvitch, Vladimir (2006) [1994]: Pensar la muerte, trad. Horacio Zabaljáuregui, Buenos Aires: Fondo de Cultura Económica.
JAY, Martin (2009): Cantos de experiencia. Variaciones modernas sobre un tema universal, trad. Gabriela Ventureira, Buenos Aires: Paidós.

JeLin, Elizabeth (2012) [2002]: Los trabajos de la memoria, Lima: Instituto de Estudios Peruanos.

Lefevere, André (1997) [1992]: Traducción, reescritura y la manipulación del canon literario, trad. María Carmen África Vidal y Román Álvarez, Salamanca: Ediciones Colegio de España.

Levi, Primo (2011) [1958]: Si esto es un hombre, trad. Pilar Gómez Bedate, Barcelona: Océano-El Aleph Editores.

LYotARD, Jean-François (1999) [1983]: La diferencia, trad. Alberto Bixio, Barcelona: Gedisa.

Mesnard, Philippe (2011): Testimonio en resistencia, trad. Silvia Kot, Buenos Aires: Waldhuter editores.

Molloy, Sylvia (2015): Vivir entre lenguas, Ciudad Autónoma de Buenos Aires: Eterna Cadencia.

PANeSI, Jorge (2004): Críticas, Buenos Aires: Norma.

POPLACK, Shana (2001): «Code-switching (Linguistic)», en Niel Smelser and Paul Baltes (eds.), International Encyclopedia of the Social and Behavioral Sciences. Elsevier Science, 2062-2065.

Rabinovich, Silvana y Perla Sneh (2011): «Alientos de exilios», en Marcelo Burello, Fabián Romandini y Emanuel Taub (eds.), Políticas del exilio. Orígenes y vigencia de un concepto. Caseros: Universidad Nacional de Tres de Febrero, 313-321.

REYes, Alfonso (1983): «De la traducción», en La experiencia literaria, México: Fondo de Cultura Económica, 130-136.

Ricceur, Paul (2005): Sobre la traducción, trad. Patricia Willson, Paidós: Barcelona.

Rousseaux, Fabiana (2009): «Memoria y verdad. Los juicios como rito restitutivo», en Eduardo Luis Duhalde et al:: Acompañamiento a testigos en los juicios contra el terrorismo de Estado. Primeras experiencias, Buenos Aires: Ministerio de Justicia, Seguridad y Derechos Humanos de la Nación. Secretaría de Derechos Humanos, 29-38.

SARLO, Beatriz (1987): «Política, ideología y figuración literaria», en Daniel Balderston et al., Ficción y política. La narrativa argentina durante el proceso militar, Buenos Aires: Alianza, 30-59.

Steiner, George (1980) [1975]: Después de Babel. Aspec- 
244 tos del lenguaje y la traducción, trad. Adolfo Castañón, México D.F.: Fondo de Cultura Económica.

STEINER, George (2000) [1976]: Lenguaje y silencio. Ensayos sobre la literatura, el lenguaje y lo inhumano, trad. Miguel Ultorio, Barcelona: Gedisa.

STEINER, George (2009) [1971]: Extraterritorial, trad. Edgardo Russo, Buenos Aires: Adriana Hidalgo.

STREJILEVICH, Nora (2006): El arte de no olvidar. Literatura testimonial en Chile, Argentina y Uruguay entre los 80 y los 90, Buenos Aires: Catálogos.

Todorov, Tzvetan (1970) [1968]: “Introducción”, en Roland Barthes et al., Lo verosímil. Buenos Aires: Tiempo Contemporáneo, 11-15.

Torop, Peeter (2010) [1995]: La traduzione totale, trad. Bruno Osimo, Milán: Hoepli.

Wittgenstein, Ludwig (1973): Tractatus logico-philosophicus, trad. Enrique Tierno Galván, Madrid: Alianza. 